\title{
Interactive Effects of Dodine and the DMI Fungicide Fenarimol in the Control of Apple Scab
}

\author{
W. Köller and W. F. Wilcox, Department of Plant Pathology, Cornell University, New York State Agricultural Ex- \\ periment Station, Geneva 14456
}

\begin{abstract}
Köller, W., and Wilcox, W. F. 2000. Interactive effects of dodine and the DMI fungicide fenarimol in the control of apple scab. Plant Dis. 84:863-870.

Interactive effects of a mixture of fenarimol and dodine in the inhibition of Venturi inaequalis populations and the risk that resistance will develop when the mixture is used for control of apple scab were investigated. Interactive mixture effects were determined for a composite population $(n=1007)$ representative of the Great Lakes apple-growing region and for a population $(n=1,295)$ sampled over three years from a single experimental orchard subjected to various fungicide treatments. Several interactive effects were identified: (i) subpopulations of $V$. inaequalis isolates resistant to dodine contained a higher proportion of isolates also resistant to fenarimol, (ii) synergistic effects were apparent for a large proportion of dodine- or fenarimolresistant isolates when tested in mixture, and (iii) the level of fenarimol resistance was higher in the subpopulation resisting the mixture than in the subpopulation resisting fenarimol alone. Interactive effects determined under in vivo test conditions were of low relevance in the control of apple scab. The partly pleiotropic resistance of dodine and fenarimol had no apparent impact on the fenarimol sensitivities of dodine-resistant populations, and expression of synergistic mixture effects were of low or no significance under orchard conditions of scab control. Treatments of apple trees with a half-rate mixture of fenarimol and dodine selected $\mathrm{V}$. inaequalis isolates resistant to the mixture. Such isolates were poorly controlled by the mixture and by each component applied alone at twice their mixture rates; therefore, mixture-resistant isolates will be selected and must be controlled by other means. The level of fenarimol resistance was high for the mixture-resistant subpopulation; therefore, increasing the mixture rate of fenarimol is unlikely to significantly improve control of these isolates. The advantage of a half-rate mixture of fenarimol and dodine in scab management resides in a substantially lower frequency of selectable isolates compared to the frequencies encountered by fenarimol and dodine applied alone.
\end{abstract}

The first fungicides active as inhibitors of sterol demethylation (DMIs) for the control of apple scab caused by Venturia inaequalis (Cooke) G. Wint. were introduced in the United States during the late 1980s $(14,15)$. Under initial conditions of baseline-sensitive populations of $V$. inaequalis, the pronounced after-infection qualities of DMIs $(32,35,36)$ allowed the design and validation of delayed-spray programs for the control of scab in orchards with low levels of inoculum (37). In such delayed-spray programs, it was recommended that DMIs be applied in mixture with a conventional protective fungicide in order to (i) supplement the sometimes weak performance of DMIs in

Corresponding author: W. Köller

E-mail:wk11@cornell.edu

This study was supported in part by USDA 9034103-539 and 94-37313-0678 and by the New York State Apple Research and Development Program.

Accepted for publication 20 April 2000.

Publication no. D-2000-0612-04R

(C) 2000 The American Phytopathological Society the control of fruit scab and (ii) implement an antiresistance strategy recommended for the control of apple scab with DMI fungicides (34). Although resistance of $V$. inaequalis populations to the DMIs has developed more slowly than to the high-risk benzimidazole fungicides (18), practical DMI resistance has been documented for an experimental orchard $(3,4)$ and for commercial orchards in Michigan (22) and Europe (25).

Two new classes of fungicides, the strobilurins $(26,29,38)$ and the anilinopyrimidines $(5,16)$, have been introduced recently for the control of apple scab. Both classes are unrelated to the DMIs, but both are prone to resistance development. At present, the relative risk of resistance of $V$. inaequalis to both groups is poorly understood. For the strobilurin kresoxim-methyl, respective studies have been initiated $(30,31,39)$. For the anilinopyrimidines, a relatively high risk of resistance has been described for Botrytis cinerea $(10,13)$; a similar risk assessment of anilinopyrimidine resistance has not been reported for $V$. inaequalis. The potential risk of resistance development to both the strobilurins and the anilinopyrimidines suggests that it would be shortsighted to discontinue the use of DMI fungicides for the management of apple scab. Thus, the design and implementation of effective strategies for managing resistance to the DMIs is important to maintaining their utility for apple scab control.

The current strategy of managing DMI resistance of $V$. inaequalis populations is to apply DMIs in mixture with conventional protective fungicides (34). The merits and limitations of this strategy have been evaluated recently (21). It was concluded that protective fungicides in mixture with DMIs will control the DMI-resistant subpopulation of $V$. inaequalis in addition to continued control provided by a DMI applied at a high rate and, thus, will delay the DMI-resistant populations from increasing to a size at which scab control will become unsatisfactory. However, frequencies of isolates resistant to DMIs will increase at a speed largely unaffected by the presence of a protective fungicide in respective mixtures (21). As the frequency of DMI-resistant phenotypes within the $V$. inaequalis population increases over time, disease control will become increasingly reliant on the contribution of the protective component of the mixture. Therefore, fungicide programs that originally were designed to exploit the postinfection properties of the DMIs (37) will gradually need to be adjusted to provide application timings that rely on the efficacy of the protective mixture component (21).

In addition to mancozeb as a conventional protective fungicide, dodine was evaluated as an alternative partner in DMI mixtures (21). In contrast to solely protective fungicides, dodine is also active in the after-infection management of scab $(2,36)$. Although practical resistance to dodine has resulted in significant loss of apple scab control in the past $(11,14,22)$, our evaluation of the mixture of DMIs with dodine under both experimental and commercial orchard conditions indicated that (i) mixtures with dodine provided apple scab control equivalent or superior to the control provided by mixtures with a conventional protectant fungicide and (ii) the DMI-dodine mixture had no adverse effects on the speed of selecting DMI- or dodine-resistant isolates (21). However, it was also noticed that DMI and dodine resistance were not entirely independent traits (21). Although the practical implications of our results obtained for a DMI mixed with a conventional protective fun- 
gicide were conclusive (21), several questions relating to the sustainability of a DMI-dodine mixture remained to be evaluated. Experimental data pertinent to this question are analyzed in this article.

\section{MATERIALS AND METHODS}

Origin of $V$. inaequalis populations. Two populations were evaluated in this study: a composite population representing orchards distributed throughout the major apple-growing regions of New York and Michigan, and a single population originating from an experimental orchard in Geneva, NY. The orchards providing the composite population of $V$. inaequalis have been described before in studies examining DMI resistance (22), dodine resistance (23), and the evaluation of antiresistance strategies (21). The majority of orchards ( $n$ $=18$ ) yielding the composite population ( $n$ $=1,007)$ were sampled in 1991 (22,23); six additional New York orchards were sampled in 1996 (23).

The experimental orchard providing the single orchard population was described recently (21) and was sampled each year from 1992 to 1994, yielding a total of 1,295 isolates for analysis. Both DMI fungicides and dodine had been tested in the orchard prior to this trial, and sensitivities of isolates of $V$. inaequalis to DMIs and dodine had shifted from baseline sensitivities to a level of resistance remaining below respective thresholds of practical resistance (22).

Sampling procedures were as described previously (21-23). Briefly, in commercial orchards, cooperating growers left several trees unsprayed until the first sporulating scab lesions developed. Diseased leaves were arbitrarily sampled from these trees,

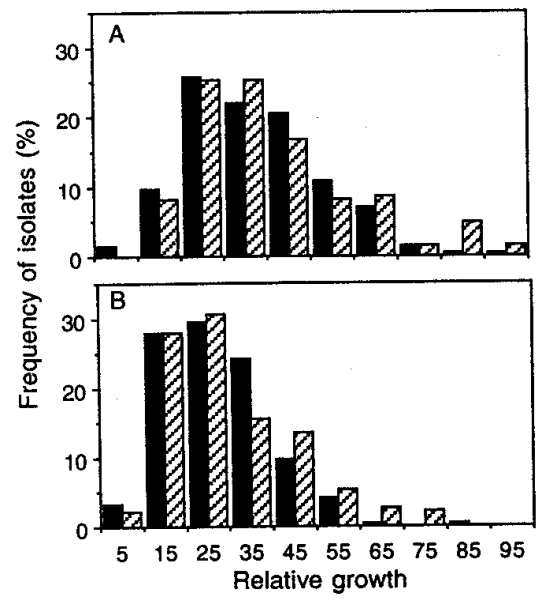

Fig. 1. Frequency distribution of fenarimol and dodine sensitivities of a Venturia inaequalis composite population $(n=186)$ baseline sensitive to both fungicides. (A) Fenarimol (closed bars) and dodine (hatched bars) sensitivity distributions. (B) Distribution of sensitivities to a half-dose mixture of fenarimol and dodine either measured (closed bars) or calculated from expected mixture effects (hatched bars). and conidia isolated from distinct lesions provided mycelium for sensitivity tests. A total of 26 to 50 monoconidial isolates were tested per orchard $(21,23)$. In the experimental orchard, diseased leaves were sampled from either untreated check trees or from trees treated with various fungicides during 1992 to 1994 (21).

Application and evaluation of fungicides. As described previously in detail (21), fungicide treatments conducted from 1992 to 1994 were arranged in a randomized complete block design with two to three trees per treatment block and three replications per treatment. Spray solutions were applied dilute to run-off; the timing of applications during the primary scab season was similar to a delayed-spray program (37), with three, five, and four applications made in 1992, 1993, and 1994, respectively. Mean spray intervals were 13 days ( 7 to 23 days); the average timing of applications was 7 days ( 3 to 14 days) after the start of the most recent infection period and 4 days ( 1 to 6 days) prior to the next following infection period. Scab incidence on terminal leaves was determined and leaves for isolate tests were sampled 2 weeks after the last sprays were applied (21). The data reported here were derived from nontreated trees or from trees treated with dodine (Syllit 65W; $290 \mathrm{mg}$ a.i./liter), fenarimol (Rubigan 1EC; $30 \mathrm{mg}$ a.i./liter), or a mixture of both fungicides at half of their single rates (21). The half-rate mixture was chosen to account for the economics of scab control.

Sensitivity tests. Fenarimol (technical grade) was obtained from Dow Agrosciences (Indianapolis, IN) and dodine (analytical standard) was from Cyanamid (Princeton, NJ). Isolation and propagation of monoconidial isolates of $V$. inaequalis and sensitivity tests were done according to the procedures described in detail previously (19-23). Conidia originating from distinct scab lesions were germinated on water agar, single germinating conidia were transferred to potato-dextrose agar (PDA), and mycelia developing from these single conidia were tested for sensitivities to fenarimol, dodine, and a half-dose mixture of fenarimol and dodine, with discriminatory doses of $0.05,0.2$, and $0.025+$ $0.1 \mu \mathrm{g} \mathrm{ml} \mathrm{m}^{-1}$, respectively. The half-dose mixture of fenarimol and dodine was chosen to reflect the half-rate mixture employed in orchard trials. Isolate sensitivities were expressed as relative growth (RG) of mycelial colonies defined as mean colony diameter on PDA amended with the fungicide per colony diameter on unamended PDA $\times 100$. Isolates with $\mathrm{RG}$ values $>80$ were rated resistant to fenarimol (22); isolates with RG values $>90$ were rated resistant to dodine (23). RG values for the half discriminatory doses of fenarimol $\left(0.025 \mu \mathrm{g} \mathrm{ml}^{-1}\right)$ and dodine $(0.1 \mu \mathrm{g}$ $\mathrm{ml}^{-1}$ ) present in the mixture were determined with isolates representative of the entire spectrum of fenarimol and dodine baseline sensitivities.

Data analysis. Sensitivities of $V$. inaequalis isolates were analyzed as described previously (21-23). All categorical data, including the frequency distribution of isolate traits, were compared according to the log linear model of SYSTAT (version 5.2; Systat, Inc., Evanston, IL). Mean RG values were compared with the nonparametric Kolmogorov-Smirnov test of SYSTAT (version 5.2; Systat, Inc.).

Additive, synergistic, or antagonistic interactions between mixture components were analyzed by applying the formula $\mathrm{E}_{\mathrm{xp}}$ $=X+Y-X Y / 100$ originally proposed by Abbott (1) and described by others $(9,12,24,28,33)$, with $E_{x p}$ as the percentage of inhibition expected from additive effects of the two mixture components, and with $X$ and $Y$ as the percentages of inhibition provided by each of the two components independently. Synergistic mixture effects are indicated, if the percentage of inhibition observed with the mixture $\left(\mathrm{O}_{\mathrm{bs}}\right)$ is higher than the expected additive effect $\left(\mathrm{O}_{\mathrm{bs}}-\mathrm{E}_{\mathrm{xp}}\right.$ $>0) ; \mathrm{O}_{\mathrm{bs}}-\mathrm{E}_{\mathrm{xp}}<0$ indicates antagonistic effects.

\section{RESULTS}

Sensitivities of $V$. inaequalis populations to a mixture of fenarimol and dodine. Baseline sensitivities of $V$. inaequalis populations to a half-dose mixture of fenarimol and dodine were determined with a composite population sampled from four commercial orchards in New York classified as baseline sensitive to both fenarimol and dodine (Fig. 1A). Mean RG values for all isolates representing this double-sensitive population were 38.3 and 41.3 for fenarimol and dodine, respectively. The mean sensitivity to fenarimol was slightly lower $(P=0.07)$ than the baseline sensitivity reported before $(\mathrm{RG}=$ 40.7) (22), whereas the mean sensitivity to dodine was not different $(P=0.67)$ from the previous baseline value $(\mathrm{RG}=40.6)$ (23). For the half-dose mixture of fenarimol and dodine, the mean RG value was 28.6.

The measured distribution of isolate sensitivities to the half-dose mixture of this baseline population was compared with the distribution of isolate sensitivities calculated from expected effects of both fungicides in mixture, based on RG values obtained at half of the normal discriminatory doses. For fenarimol, RG values at the dose of $0.025 \mu \mathrm{g} \mathrm{ml}^{-1}$ were increased by 15 (standard deviation $[\mathrm{SD}]=7 ; n=36$ ) relative to the full discriminatory dose of 0.05 $\mu \mathrm{g} \mathrm{ml}^{-1}$; for dodine, $\mathrm{RG}$ values at $0.1 \mu \mathrm{g}$ $\mathrm{ml}^{-1}$ were increased by $14(\mathrm{SD}=5 ; n=10)$ compared to the full discriminatory dose of $0.2 \mu \mathrm{g} \mathrm{ml}^{-1}$. The measured and calculated mean RG values (28.6 and 30, respectively) as well as the measured and calculated distributions of isolate frequencies (Fig. 1B) were not significantly different 
( $P=0.58$ and 0.19 , respectively), indicating that the method for calculating expected mixture sensitivities employed below was adequately precise within the population context analyzed in this study.

Sensitivities of isolates to the half-dose mixture were also determined for a composite population representing eight orchards baseline sensitive to fenarimol but resistant to dodine (Fig. 2A). RG values of the composite population were 41.4 for fenarimol and 76.5 for dodine; frequencies of resistant isolates were $1.4 \%$ for fenarimol and $40.1 \%$ for dodine. The mean RG values and frequencies of resistant isolates were not different $(P \geq 0.46)$ from data reported before for fenarimol-baseline (22) and dodine-resistant populations (23). For this fenarimol-sensitive and dodine-resistant population, the mean RG value determined for the half-dose mixture of fenarimol and dodine was 48.2. The frequency distribution of isolate sensitivities to the mixture remained unimodal (Fig. 2B) rather than following the bimodal distribution of dodine sensitivities typical for dodine-resistant populations (23). As expected, the mean RG value determined for the half-dose mixture was significantly lower $(P<0.001)$ than the mean RG value determined for dodine and significantly higher $(P<0.001)$ than the mean value determined for fenarimol.

Interactive effects of fenarimol and dodine on $\boldsymbol{V}$. inaequalis isolates. It had been reported for a population of $V$. inaequalis sampled from an experimental orchard that the frequency of fenarimol-resistant isolates within the dodine-resistant subpopulation was significantly higher than in the dodine-sensitive subpopulation (21). This partial interdependence of DMI and dodine resistance was confirmed in

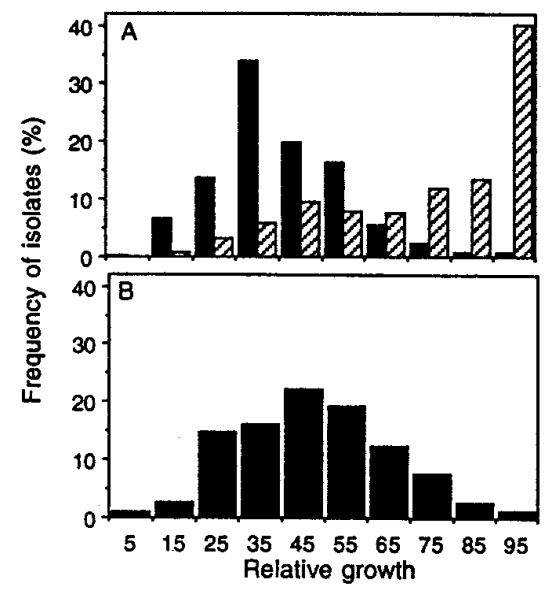

Fig. 2. Frequency distribution of fenarimol and dodine sensitivities of a Venturia inaequalis composite population baseline sensitive to fenarimol and resistant to dodine $(n=292)$. (A) Fenarimol (closed bars) and dodine (hatched bars) sensitivity distribution. (B) Distribution of sensitivities to a half-dose mixture of fenarimol and dodine. this study for a composite population of $V$. inaequalis isolates sampled from a total of 24 orchards representative of the entire Great Lakes apple-growing region. The frequency of fenarimol-resistant isolates and the mean RG values obtained for fenarimol were higher in the dodine-resistant than in the dodine-sensitive subpopulation (Table 1). Consistent with a pleiotropic relationship between dodine and fenarimol resistance, both the measured and calculated RG values for the half-dose mixture of fenarimol and dodine were also significantly higher for the fenarimol-resistant subpopulation (Table 1). For the fenarimolresistant subpopulation, the measured mean RG value of the half-dose mixture was significantly lower $\left(P=0.002 ; \mathrm{O}_{\mathrm{bs}}-\right.$ $\left.\mathrm{E}_{\mathrm{xp}}=16.3 \%\right)$ than the $\mathrm{RG}$ value expected from purely additive effects of the two mixture components (Table 1). This result indicated a potentially synergistic effect of dodine on fenarimol-resistant isolates superimposed on the positively correlated interdependence of fenarimol and dodine resistance determined singly for each of the mixture components.

The presence of synergistic effects was investigated in greater detail by analyzing distinct subpopulations of the same composite population of $V$. inaequalis isolates. For the subpopulation representing a narrow range of double-sensitive isolates ( $R G$ $=30$ to 50 for both fenarimol and dodine), the isolate distribution of interactive mixture effects was symmetrical and centered around zero (Fig. 3), the value indicative for purely additive effects of both mixing partners. For the dodine- or fenarimol-resistant subpopulations, distributions of isolate frequencies were shifted significantly $(P<0.001)$ toward higher frequencies within the range of positive values (Fig. 3), indicating a synergistic interaction of the mixture components. These differences were not caused by potential limitations inherent in our method of quantifying synergistic effects described by Levy et al. (28), because positive values for the difference $\mathrm{O}_{b s}-\mathrm{E}_{\mathrm{xp}}$ could have been higher by
$>25 \%$ for all isolates analyzed.

The identical analysis of subpopulations of isolates $(n=1,295)$ sampled from the experimental orchard described recently (21) produced very similar results (Fig. 4). Interactive mixture effects on isolates belonging to the double-sensitive subpopulation were, again, centered around zero, whereas the differences between observed and expected mixture sensitivities indicated very similar synergistic effects for isolates resistant to dodine or fenarimol (Fig. 4). Excluding isolates exhibiting double resistance to both fenarimol and dodine had no effect on the outcome of the analysis (data not shown). Moreover, the distributions of the $\mathrm{O}_{\mathrm{bs}}-\mathrm{E}_{\mathrm{xp}}$ isolate frequencies obtained for the two dodine- and fenarimol-resistant subpopulations (Figs. 3 and 4) were not significantly different $(P=$ 0.13 and 0.37 , respectively), indicating that these mixture effects were a general trait of $V$. inaequalis subpopulations resistant to fenarimol, dodine, or both.

For both double-sensitive subpopulations described in Figures 3 and 4, 94\% of all isolates exhibited differences between observed and expected mixture effects within the range of -15 to $15 \%$. This variation reflected, most likely, the lack of precision inherent to the sensitivity test (22) and, possibly, the additional expression of marginal antagonistic and synergistic effects. Thus, differences within this range were rated as additive, while respective differences with values of $<-15 \%$ and $>15 \%$ were rated as indicative of antagonistic or synergistic effects, respectively (Table 2). The frequencies of synergized isolates were significantly higher for both the dodine- and the fenarimol-resistant subpopulations than for respective doublesensitive subpopulations (Table 2). The elevated frequencies of synergized isolates observed for the fenarimol-resistant relative to the dodine-resistant subpopulations (Table 2) were highly significant $(P<$ $0.001)$, indicating that the synergistic effects of dodine on fenarimol-resistant isolates was more pronounced than the syner-

Table 1. Relationship between resistance of Venturia inaequalis isolates to fenarimol and dodine

\begin{tabular}{|c|c|c|c|c|}
\hline \multirow[b]{2}{*}{ Fungicide $^{b}$} & \multirow[b]{2}{*}{ Parameter } & \multicolumn{2}{|c|}{ Fenarimol subpopulations ${ }^{\mathrm{a}}$} & \multirow[b]{2}{*}{$P^{\mathbf{c}}$} \\
\hline & & $\mathbf{S}$ & $\mathbf{R}$ & \\
\hline \multirow[t]{2}{*}{ Dodine $\mathrm{R}^{\mathrm{d}}$} & & 16.8 & 30.0 & 0.06 \\
\hline & Mean RG & 58.5 & 70.0 & $<0.01$ \\
\hline Fenarimol & Mean RG obs ${ }^{\mathrm{e}}$ & 38.0 & 63.1 & $<0.01$ \\
\hline + Dodine & Mean RG exp & 40.6 & 79.4 & $<0.01$ \\
\hline
\end{tabular}

${ }^{\text {a }}$ Subpopulations analyzed were categorized as sensitive (S; relative growth $[\mathrm{RG}] \leq 80, n=977$ ) or resistant (R; RG > 80; $n=30$ ) to fenarimol.

${ }^{\mathrm{b}}$ Isolate sensitivities to dodine were tested at a discriminatory dose of $0.2 \mu \mathrm{g} \mathrm{ml}^{-1}$; isolate sensitivities to the mixture of fenarimol and dodine were tested at $0.025 \mu \mathrm{g} \mathrm{ml}^{-1}$ fenarimol and $0.1 \mu \mathrm{g} \mathrm{ml}^{-1}$ dodine.

${ }^{c}$ Comparison of counts of isolates classified as sensitive $(\mathrm{RG} \leq 90)$ or resistant $(\mathrm{RG}>90)$ to dodine (log-linear model) or comparison of mean RG values (Kolmogorov-Smirnov test).

${ }^{\mathrm{d}}$ Frequency $(\%)$ of dodine-resistant $(\mathrm{R})$ isolates $(\mathrm{RG}>90)$ within the fenarimol-sensitive or -resistant subpopulations.

${ }^{\text {e }}$ Mean measured RG values (obs) derived from tests with a half-dose mixture of fenarimol and dodine, and mean RG values calculated (exp) from interactive effects of the mixture components. 
gistic effect of fenarimol on dodineresistant isolates. Frequencies of isolates assigned to the three categories of antagonistic, additive, and synergistic mixture effects were not significantly different $(P \geq$ 0.19 ) for the two separate populations of $V$. inaequalis analyzed.

Responses of populations to treatments with a half-rate mixture of fenarimol and dodine. The definition of

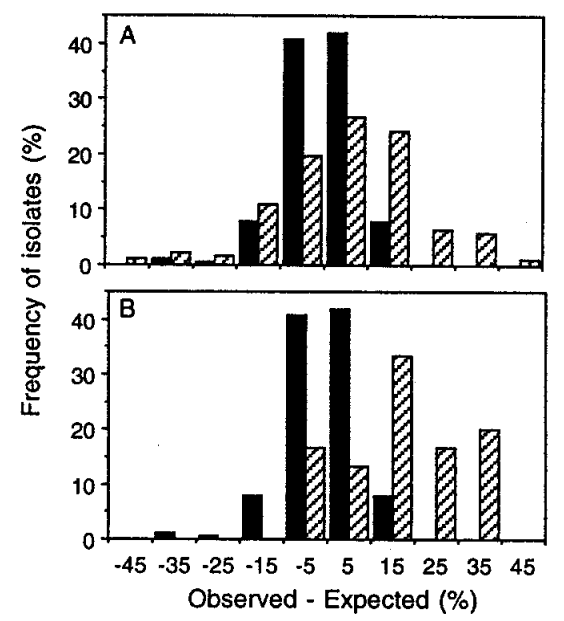

Fig. 3. Interactive effects of fenarimol and dodine in mixture on the sensitivity distribution of a Venturia inaequalis composite population. Percentages of inhibition calculated for additive effects of fungicide action (Expected) were subtracted from measured percentages of inhibition (Observed). Isolates were either double sensitive (closed bars) to fenarimol and dodine (relative growth $=30$ to $50 ; n=177$ ) or resistant (hatched bars) to (A) dodine $(n=173)$, (B) fenarimol $(n=30)$, or both.

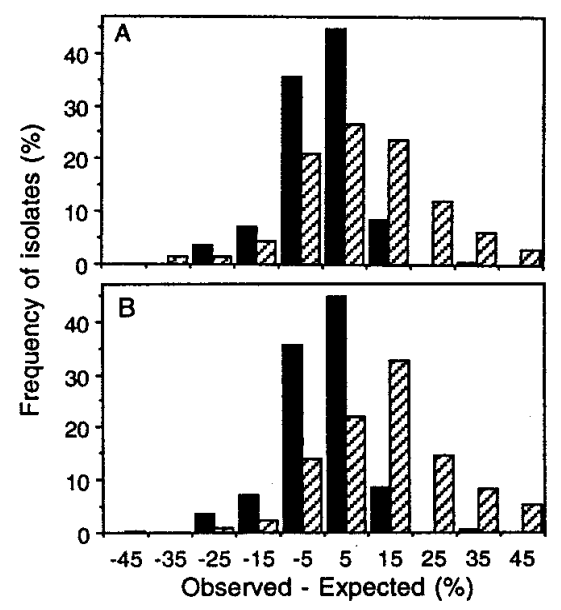

Fig. 4. Interactive effects of fenarimol and dodine in mixture on the sensitivity distribution of a single orchard population of Venturia inaequalis. Percentages of inhibition calculated for additive effects of fungicide action (Expected) were subtracted from measured percentages of inhibition (Observed). Isolates were either double sensitive (closed bars) to fenarimol and dodine (relative growth $=30$ to $50 ; n=141$ ) or resistant (hatched bars) to (A) dodine $(n=206)$ or $(\mathbf{B})$ fenarimol $(n=264)$. sensitivities classifying $V$. inaequalis as resistant to the DMIs fenarimol and myclobutanil $(\mathrm{RG}>\mathrm{80})$ or to dodine $(\mathrm{RG}>$ 90) had been derived from comparisons of frequency distributions of isolate sensitivities found in baseline populations with distributions in orchards where the fungicides had failed to provide acceptable control of apple scab $(22,23)$. Although baseline data for the half-dose mixture of fenarimol and dodine could be provided in this study (Fig. 1), a threshold level of resistance could not be established, because commercial control failures with DMIs in mixture with dodine have not been documented and analyzed. Therefore, the definition of isolate sensitivities classified as resistant to the half-rate mixture of fenarimol with dodine was derived from the response of $V$. inaequalis isolates to the treatment with the mixture over the course of our trials in the experimental orchard. Comparison of isolate frequencies between populations sampled from nontreated and treated trees revealed that the frequency of isolates with RG values $>90$ to the halfdose mixture had increased most substantially by a factor of 5.7 (Fig. 5). This sen-

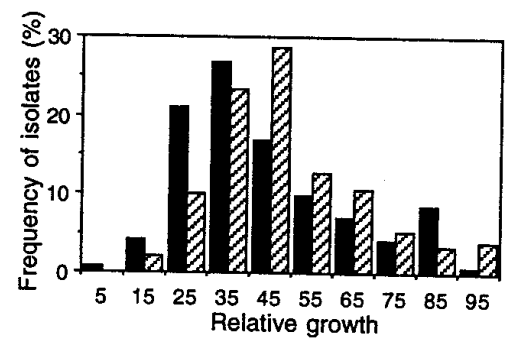

Fig. 5. Frequency distribution of sensitivities of Venturia inaequalis isolates to a half-dose mixture of fenarimol and dodine. Isolates were sampled from nontreated trees (closed bars; $n=$ 142) or from trees treated with a half-dose mixture of both fungicides (hatched bars; $n=$ 150).

Table 2. Interactive effects of dodine and fenarimol in subpopulations of Venturia inaequalis isolates

\begin{tabular}{|c|c|c|c|c|}
\hline \multirow[b]{2}{*}{ Population $^{\mathrm{b}}$} & \multirow[b]{2}{*}{ Effects $^{\mathbf{c}}$} & \multicolumn{3}{|c|}{ Subpopulations $^{\mathrm{a}}$} \\
\hline & & Sensitive (\%) & Dodine-resistant (\%) & Fenarimol-resistant (\%) \\
\hline \multirow[t]{3}{*}{ Composite } & Antagonistic & 4.0 & 5.2 & 0 \\
\hline & Additive & 93.8 & 75.1 & 43.3 \\
\hline & Synergistic & 2.2 & 19.7 & 56.1 \\
\hline$n$ & $\ldots$ & 177 & 173 & 30 \\
\hline$P^{\mathrm{d}}$ & $\ldots$ & & $<0.01$ & $<0.01$ \\
\hline \multirow[t]{3}{*}{ Single orchard } & Antagonistic & 5.0 & 4.4 & 1.5 \\
\hline & Additive & 93.6 & 68.0 & 56.4 \\
\hline & Synergistic & 1.4 & 27.7 & 42.1 \\
\hline$n$ & $\ldots$ & 141 & 206 & 264 \\
\hline$P^{\mathrm{d}}$ & $\ldots$ & $\ldots$ & $<0.01$ & $<0.01$ \\
\hline
\end{tabular}

a Subpopulations represent isolates sensitive (relative growth $[R G]=30$ to 50 ) to both fenarimol and dodine (sensitive), resistant to dodine ( $R G>90)$, or resistant to fenarimol ( $R G>80)$.

${ }^{\mathrm{b}}$ Isolate sensitivities were combined for populations of 24 orchards distributed throughout New York and Michigan (composite) or combined for isolate sensitivities sampled from the experimental orchard in Geneva, NY (21).

${ }^{\mathrm{c}}$ Interactive effects were rated antagonistic, additive, or synergistic for differences of Obs - Exp of $<-15,-15$ to 15 , and $>15$, respectively.

${ }^{\mathrm{d}}$ Comparison of counts of isolates classified into the groups of antagonistic, additive, and synergistic interactions (log-linear model). 
dodine. Control of leaf scab caused by the subpopulation of $V$. inaequalis reflecting a high sensitivity ( $R G=0$ to 70 ) to the halfdose mixture was equivalent for all treatments (Table 5). The subpopulation with mixture sensitivities intermediate between fully sensitive and resistant classifications ( $R G=71$ to 90 ) was most effectively controlled by the half-rate mixture; the low statistical significance obtained for the dodine treatment (Table 5) was caused by a when dodine was applied alone (22). Control achieved for isolates classified as resistant to the half-dose mixture $(\mathrm{RG}>90)$ was poor for all treatments and significantly lower $(P<0.01)$ than for isolates with intermediate sensitivities, confirming the classification of this RG range as resistant to the mixture (Fig. 5). No treatment including the half-rate mixture altered the frequencies of isolates synergized by the half-dose mixture under in vitro test conditions (Table 6).

Levels of scab control achieved for isolates double sensitive to fenarimol and dodine were equivalent for the half-rate mixture and the two components applied singly at their full rates (Table 7). Although double-resistant isolates were controlled less effectively than the doublesensitive isolates by all treatments $(P<$ 0.01 ), the level of control was highest with the half-rate mixture (Table 7). The low level of control of both mixture-resistant (Table 5) and double-resistant (Table 7) isolates achieved with dodine was comparable to the control of dodine-resistant large season-to-season variation in control

isolates reported previously (22). However, the lack of control of mixture- and doubleresistant (Tables 5 and 7 , respectively) isolates by fenarimol was significantly lower $(P<0.01)$ than the $54 \%$ level of control achieved for the entire fenarimolresistant subpopulation (22). This discrepancy might be explained by a higher proportion of isolates with high levels of fenarimol resistance within the double- and mixture-resistant subpopulations. The frequency of isolates highly fenarimol resistant $(\mathrm{RG}>95)$ selected by treatments with fenarimol was $31 \%$; it was $61 \%$ for the double- and mixture-resistant subpopulations $(P=0.03)$.

\section{DISCUSSION}

The purpose of mixing fungicides is to (i) broaden the spectrum of diseases controlled or (ii) delay or manage fungicide resistance $(7,9,12,17)$. The most prominent mixture strategy aimed at fungicide resistance, which was proposed originally as a response to resistance developing to the benzimidazole fungicides (6), has been to mix conventional protective fungicides with a newly introduced fungicide prone to resistance development (17). This strategy has been recommended for DMI fungicides used to control apple scab (34).

A general obstacle to the use of fungicide mixtures employed in antiresistance strategies has been the increased cost of disease control relative to the use of single compounds. For polycyclic diseases such as apple scab, the annual cost of disease control is not determined by the cost of a

Table 3. Impact of fungicide treatments on the selection of Venturia inaequalis isolates resistant to a half-dose mixture of fenarimol and dodine

\begin{tabular}{|c|c|c|c|c|}
\hline \multirow[b]{2}{*}{ Parameters } & \multirow[b]{2}{*}{ Check $^{b}$} & \multicolumn{3}{|c|}{ Treatments $^{\mathrm{a}}$} \\
\hline & & Fenarimol (15) + dodine (145) & Fenarimol (30) & Dodine (290) \\
\hline$n$ & 142 & 150 & 149 & 150 \\
\hline Resistant $^{\mathrm{c}}$ & 0.7 & 4.0 & 6.0 & 6.7 \\
\hline$P^{\mathrm{d}}$ & $\ldots$ & 0.1 & 0.01 & $<0.01$ \\
\hline
\end{tabular}

${ }^{a}$ Rates of fungicides (grams a.i./1,000 liters) are given in parentheses.

${ }^{\mathrm{b}}$ Isolates collected from nontreated trees.

${ }^{c}$ Frequencies $(\%)$ of isolates resistant (relative growth $\left.[R G]>90\right)$ to the half-dose mixture of fenarimol and dodine.

${ }^{\mathrm{d}}$ Comparison of counts of isolates classified as mixture-sensitive $(\mathrm{RG} \leq 90)$ or mixture-resistant $(\mathrm{RG}$ > 90) obtained from nontreated trees with respective counts for isolates obtained from trees treated as specified (log linear model). single fungicide application but rather by the cost of multiple sprays in a season-long control program. Thus, when DMI fungicides were introduced for scab control in the United States, programs were developed (37) that balanced the relatively high per-application cost of a DMI-plus-protectant fungicide mixture with a protocol requiring a reduced number of seasonal applications. Reduction in the number of seasonal sprays was predicated on complementing the postinfection activity of the DMIs with a protective fungicide, which is significant only for applications made prior to an infection period (37). Subsequent evaluation of this mixture strategy (21) revealed that a protectant in mixture with a DMI will provide additional control of both the DMI-sensitive and -resistant subpopulation of $V$. inaequalis, but that the speed of selecting DMI-resistant subpopulations will not be slowed down (21). Therefore, it was recommended that the timing of fungicide applications should be gradually adjusted to a protective schedule, rather than an after-infection schedule originally favored by the DMIs, as frequencies of DMI-resistant isolates increase (37). Consequently, control programs that rely upon postinfection activities will gradually decrease in value until it might become equally efficacious and economical to revert to programs based upon full rates of a protectant alone.

Sustaining after-infection qualities of fungicide mixtures demands that both mixture components are active in an afterinfection mode of application; thus, it also implies that both components will be systemic and most likely prone to resistance development. In this study, we have analyzed the merits and limitations of a dodine-DMI mixture employed in the control of apple scab. Both components are active in the after-infection mode of control (36) and both components have experienced practical resistance $(22,23)$. Each also belongs to a group of fungicides characterized by a quantitative resistance response of populations $(22,23)$, with resistant isolates still partially controlled at high doses of the respective fungicides (21). As described recently (21), a half-rate mixture of dodine and the DMI fenarimol provided

Table 4. Impact of fungicide treatments on the selection of Venturia inaequalis isolates resistant to both fenarimol and dodine

\begin{tabular}{|c|c|c|c|c|c|c|c|}
\hline \multirow[b]{2}{*}{ Treatment $^{b}$} & \multirow[b]{2}{*}{ Rate (mg a.i./liter) } & \multirow[b]{2}{*}{$n$} & \multicolumn{5}{|c|}{ Frequencies of resistant isolates $(\%)^{a}$} \\
\hline & & & $\begin{array}{l}\text { Double R (obs) } \\
\text { R }\end{array}$ & $P^{c}$ & Fen $R$ & Dod R & Double R (exp) \\
\hline None & 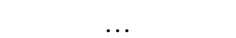 & 142 & 1.4 & & 11.3 & 9.9 & 1.1 \\
\hline $\begin{array}{l}\text { Fenarimol } \\
+ \text { Dodine }\end{array}$ & $\begin{array}{r}15 \\
+145\end{array}$ & 150 & 4.7 & 0.10 & 21.3 & 16.7 & 3.6 \\
\hline Fenarimol & 30 & 149 & 7.4 & 0.01 & 26.2 & 19.5 & 5.1 \\
\hline Dodine & 290 & 150 & 10.7 & $<0.01$ & 23.3 & 26.7 & 6.2 \\
\hline
\end{tabular}

a Observed frequencies double-resistant isolates (Double R [obs]) describe isolates resistant to both fenarimol (Fen; relative growth [RG] > 80) and dodine (Dod; RG > 90). Expected frequencies of double-resistant isolates (Double R [exp]) were calculated from the frequencies of isolates either resistant to fenarimol $(\mathrm{RG}>80)$ or dodine $(\mathrm{RG}>90)$ by multiplying respective frequencies.

${ }^{\mathrm{b}}$ Fenarimol and dodine were applied as Rubigan 1EC and Syllit 65WP, respectively.

${ }^{c}$ Comparison of counts of isolates classified sensitive or singly resistant to fenarimol and dodine or double-resistant obtained from nontreated trees with respective counts for isolates obtained from trees treated as specified (log linear model). 
equivalent or superior control of scab relative to the DMI mixed with a protective fungicide and did not accelerate the selection of either DMI- or dodine-resistant subpopulations. Thus, our focus of the present study was on the risk of selecting isolates resisting the half-rate mixture.

For mixtures of two fungicides with each component prone to resistance, the importance of synergistic effects of the mixture components has been discussed frequently $(7,9,12,24)$. The absence or presence of such synergistic effects is determined by the genetic background of individual $V$. inaequalis isolates; therefore, our analysis was based on testing the sensitivities of large populations, sampled from either 24 orchards distributed across the Great Lakes apple-growing region or a single experimental orchard population over time. Various interactions between fenarimol and dodine were identified and evaluated. Data described previously for the single orchard population (21) showed

Table 5. Control of leaf infections by Venturia inaequalis subpopulations with different sensitivities to a half-dose mixture of fenarimol and dodine

\begin{tabular}{lcccc}
\hline & & \multicolumn{3}{c}{ Mean control of subpopulations $(\boldsymbol{\%})^{\mathbf{a}}$} \\
\cline { 3 - 5 } Treatment $^{\mathbf{b}}$ & Rate (milligrams a.i./liter) & $\mathbf{0 - 7 0}$ & $\mathbf{7 1 - 9 0}$ & $>\mathbf{9 0}$ \\
\hline Fenarimol & 15 & $85(5.9)$ & $89(2.6)$ & $13(14)$ \\
+ Dodine & 145 & & & \\
Fenarimol & 30 & $82(4.3)$ & $78(5.8)$ & 0 \\
Dodine & 290 & $81(7.8)$ & $70(20)$ & $9(16)$ \\
$P($ Fenarimol) & & 0.21 & 0.03 & $<0.01$ \\
$P$ (Dodine) $^{\mathbf{c}}$ & $\ldots$ & 0.62 & 0.15 & 0.7 \\
\hline
\end{tabular}

${ }^{a}$ The levels of control (relative to the untreated check) achieved for three subpopulations were calculated from disease incidences recorded for the various treatments in each year (21) and from the mean frequencies of isolates in the three sensitivity ranges recovered from trees subjected to respective treatments. The sensitivity ranges reflect relative growth values of isolates determined with the half-dose mixture of fenarimol and dodine. Standard deviations are given in parentheses.

${ }^{\mathrm{b}}$ Fenarimol and dodine were applied as Rubigan 1EC and Syllit 65 WP, respectively.

${ }^{c}$ Significance of differences between mean percentages of control achieved with a half-rate mixture compared to the control achieved with the full rate of fenarimol or dodine applied singly (analysis of variance).

Table 6. Interactive effects of dodine and fenarimol on populations of Venturia inaequalis recovered from apple trees subjected to different fungicide treatments

\begin{tabular}{lcccc}
\hline & & \multicolumn{3}{c}{ Frequencies by treatments (\%) $^{\mathbf{a}}$} \\
\cline { 4 - 6 } Effects $^{\mathbf{b}}$ & Check $^{\mathbf{c}}$ & Fenarimol (15)+ dodine (145) & Fenarimol (30) & Dodine (290) \\
\hline Antagonistic & 2.8 & 7.0 & 8.7 & 4.0 \\
Additive & 75.4 & 72.5 & 69.8 & 76.0 \\
Synergistic & 21.8 & 26.1 & 21.5 & 20.0 \\
$n$ & 142 & 150 & 149 & 150 \\
$P^{\mathrm{d}}$ & $\ldots$ & 0.22 & 0.09 & 0.81 \\
\hline
\end{tabular}

a Rates of fungicides (grams a.i./1,000 liters) are given in parentheses.

${ }^{\mathrm{b}}$ Interactive effects were rated antagonistic, additive or synergistic for differences of Obs - Exp of $<-15,-15$ to 15 , and $>15$, respectively.

${ }^{\mathrm{c}}$ Isolates collected from nontreated trees

${ }^{\mathrm{d}}$ Comparison of counts of isolates classified into the groups of antagonistic, additive and synergistic interactions (log-linear model).

Table 7. Control of Venturia inaequalis subpopulations double resistant to fenarimol and dodine

\begin{tabular}{lccc}
\hline & & \multicolumn{2}{c}{ Mean control of subpopulations $(\%)^{\mathbf{a}}$} \\
\cline { 3 - 4 } Treatment $^{\mathbf{b}}$ & Rate (milligrams a.i./liter) & Sensitive & Double-resistant \\
\hline Fenarimol & 15 & $89(4)$ & $57(6)$ \\
+ Dodine & 145 & $\ldots$ & $\ldots$ \\
Fenarimol & 30 & $84(9)$ & $7(6)$ \\
Dodine & 290 & $80(13)$ & $21(36)$ \\
$P$ (Fenarimol) $^{\mathbf{c}}$ & $\ldots$ & 0.46 & $<0.01$ \\
$P$ (Dodine) $^{\mathbf{c}}$ & $\ldots$ & 0.35 & 0.16 \\
\hline
\end{tabular}

a The levels of control (relative to the untreated check) achieved for subpopulations double sensitive or sensitive to either fenarimol or dodine (sensitive) or resistant to both fenarimol and dodine (double resistant) were calculated from disease incidences recorded for the various treatments in each year (21) and the mean frequencies of isolates sensitive or double resistant to fenarimol and dodine. Isolate sensitivities to fenarimol and dodine were determined at full discriminatory doses. Standard deviations are given in parentheses.

${ }^{\mathrm{b}}$ Fenarimol and dodine were applied as Rubigan 1EC and Syllit 65WP, respectively.

${ }^{c}$ Significance of differences between mean percentages of control achieved with a half-rate mixture compared to the control achieved with the full rates of fenarimol or dodine applied singly (analysis of variance). that resistance of $V$. inaequalis to dodine and DMIs was not an entirely independent trait, with an elevated frequency of DMIresistant isolates identified in the dodineresistant subpopulation. This partial interdependence was confirmed in the present study for a large composite population. However, it was also noticed that the selection of dodine-resistant isolates to a frequency of practical resistance had no detectable impact on DMI resistance (Fig. 2), suggesting that genotypes containing such pleiotropically active genes are either very infrequent or poorly competitive in populations of $V$. inaequalis.

Further analysis of both the single orchard population and the representative composite population of $V$. inaequalis revealed that the interactive effects of dodine and fenarimol in mixture were complex. Interactive effects were either antagonistic, additive, or synergistic. Synergistic effects were most pronounced for isolates from the dodine- and DMI-resistant subpopulations. Moreover, the synergistic effects of dodine on DMI-resistant isolates were significantly higher than the converse. Synergistic effects of dodine on DMI-resistant fungi have been described previously for laboratory mutants of Aspergillus nidulans and Penicillium italicum (7,9). Mechanistically, these effects were discussed in relation to an active efflux mechanism of DMI resistance presumed to be active in the expression of pleiotropic resistance $(8,9)$. Within the population context of $V$. inaequalis examined in the present study, such synergistic mixture effects were apparent for only part of the DMI- or dodine-resistant subpopulations of $V$. inaequalis, suggesting multiple mechanisms of both DMI and dodine resistance.

Synergistic effects demonstrated under in vitro test conditions are not necessarily expressed during the control of diseases. In order to be relevant, both mixture components must act simultaneously on the pathogen. Separation of the mixture components in space (e.g., systemic versus surface protective properties of mixture components) or differential activities on the various stages of disease development can be expected to minimize the impact of such synergistic effects under in vivo conditions. Differential activities on the various stages of scab development have been reported for dodine and fenarimol (36). Dodine was superior to fenarimol in a protective application mode, whereas fenarimol was substantially more active than dodine when applied within 3 days after infection. Both fungicides were equally potent in presymptom applications (5 to 7 days after infection), defined as leading to chlorotic but nonsporulating lesions; antisporulant activities were apparent only for dodine. Consequently, significant synchronous action of fenarimol and dodine appears to be restricted to only one of the several stages of scab development. 
The impact of synergistic interactions between dodine and fenarimol expressed in vitro were evaluated in orchard trials of apple scab control. All orchard data suggest that the synergistic mixture effects expressed under in vitro test conditions were of impractical significance with respect to disease control, most likely because stages of synchronous action are limited. For instance, synergistic mixture effects should have reduced the selection of double-resistant isolates by the mixture relative to the individual components, because part of the double-resistant subpopulation should have been synergized and, thus, preferentially controlled. Although such reduction did occur numerically (Table 4), the differences with respect to dodine and fenarimol applied singly were of marginal significance. Furthermore, if synergistic mixture effects were active in vivo, the mixture should have selected preferentially fenarimol- and dodine-resistant isolates not synergized under in vitro test conditions. This expectation was not verified by the test results, as indicated by virtually identical frequencies of nonsynergized isolates sampled from trees subjected to all treatments (Table 6).

In the absence of significant synergistic effects in vivo, a positive feature of the low-rate mixture of fenarimol and dodine lies in a substantially reduced frequency of selectable mixture- and double-resistant isolates compared to the frequencies of isolates resistant to only one of the mixture components. As is apparent from the data presented throughout the study and in Table 8 , the frequency of mixture-resistant isolates will be lower than for either component alone. This effect of lowering the frequency of selectable isolates with fungicide mixtures comprises a general antiresistance strategy for mixtures containing two fungicides prone to resistance development.

Although the frequency of $V$. inaequalis isolates resisting the mixture of fenarimol and dodine will be substantially lower than the frequency of isolates resistant to either one of the mixture components, the poor control of such isolates must become the focus of antiresistant strategies aimed at the mixture. The level of fenarimol resistance was higher for mixture-resistant isolates than for the total of fenarimol-resistant isolates; therefore, the speed of selection is unlikely to be slowed substantially by increasing the mixture rate of fenarimol, a strategy recommended for mixtures of DMIs with protective fungicides (21). Consequently, the mixture-resistant population would have to be controlled by other means. Options are to include a protective fungicide in addition or to limit the number of seasonal sprays by rotating the mixture with unrelated fungicides active in apple scab control.

Our experimental approach of evaluating the relative merits of an antiresistance strategy based on a fenarimol-dodine mixture was based on (i) testing interactive in vitro effects in the context of large populations of $V$. inaequalis and (ii) evaluating the relevancy of such interactive mixture effects under orchard conditions of scab control. This approach should be applicable to other host-pathogen systems and to other mixtures containing more than one

Table 8. Resistance status of Venturia inaequalis populations

\begin{tabular}{|c|c|c|c|}
\hline \multirow[b]{2}{*}{ Population $^{\text {b }}$} & \multicolumn{3}{|c|}{ Frequency $(\%)^{\mathbf{a}}$} \\
\hline & Fenarimol-resistant & Dodine-resistant & Mixture-resistant \\
\hline Experimental & 11.3 & 9.9 & 0.7 \\
\hline Dodine-resistant & 0.7 & 40.1 & 1.4 \\
\hline 1 & 3.6 & 28.9 & 0 \\
\hline 2 & 0 & 30.0 & 2.5 \\
\hline 3 & 3.8 & 42.3 & 3.8 \\
\hline 4 & 0 & 8.7 & 0 \\
\hline 5 & 0 & 8.7 & 0 \\
\hline 6 & 0 & 25.7 & 0 \\
\hline 7 & 2.2 & 52.0 & 0 \\
\hline 8 & 0 & 55.0 & 3.4 \\
\hline 9 & 0 & 31.5 & 0 \\
\hline 10 & 6.8 & 0 & 0 \\
\hline 11 & 5.0 & 15.0 & 0 \\
\hline 12 & 10.0 & 12.0 & 0 \\
\hline 13 & 2.0 & 48.0 & 2.0 \\
\hline 14 & 4.0 & 10.0 & 0 \\
\hline 15 & 10.0 & 10.0 & 0 \\
\hline 16 & 4.0 & 24.0 & 2.0 \\
\hline
\end{tabular}

${ }^{a}$ Isolates were rated resistant to fenarimol, dodine, and the half-dose mixture, if their relative growth values at the discriminatory doses were $>80,>90$, and $>90$, respectively. Due to the sample sizes analyzed, zero values reflect frequencies of $<5 \%$ (27).

${ }^{\mathrm{b}}$ With the exception of the experimental orchard (Experimental; $n=142$ ) and the dodine-resistant but fenarimol-sensitive composite population (Dodine-resistant; $n=292$ ), all other populations were from individual commercial orchards sampled in 1991 (1 through 11) and 1996 (12 through 16), with sample sizes ranging from 26 to 50 and with levels of resistance to fenarimol, dodine, or both significantly higher than baseline.

component prone to resistance development.

\section{ACKNOWLEDGMENTS}

We thank Dow Agrosciences and United Agri Products for financial aid and for providing commercial fungicides; and J. A. Burr, J. R. Nevill, and C. A. Smith for their assistance. This article is dedicated to M. Szkolnik on the occasion of his 80th birthday.

\section{LITERATURE CITED}

1. Abbott, W. S. 1925. A method of computing the effectiveness of an insecticide. J. Econ. Entomol. 18: 265-267.

2. Albert, J. J., and Lewis, F. H. 1962. Effect of repeated applications of dodine and of captan on apple scab foliage lesions. Plant Dis. Rep. 46: 163-167.

3. Braun, P. G. 1994. Development and decline of a population of Venturia inaequalis resistant to sterol-inhibiting fungicides. Norw. J. Agric. Sci. 17(Suppl.):173-184.

4. Braun, P. G., and McRae, K. B. 1992. Composition of a population of Venturia inaequalis resistant to myclobutanil. Can. J. Plant Pathol. 14:215-220.

5. Daniels, A., Birchmore, R. J., and Winter, E. H. 1994. Activity of pyrimethanil on Venturia inaequalis. Proc. Brighton Crop Prot. Conf. 1994:525-532.

6. Delp, C. 1980. Coping with resistance to plant disease control agents. Plant Dis. 64:652-657.

7. De Waard, M. 1996. Synergism and antagonism in fungicide mixtures containing sterol demethylation inhibitors. Phytopathology 86:1280-1283.

8. De Waard, M. A. 1997. Significance of ABC transporters in fungicide sensitivity and resistance. Pestic. Sci. 51:271-275.

9. De Waard, M. A., and Gisi, U. 1995. Synergism and antagonism in fungicides. Pages 565-578 in: Modern Selective Fungicides, 2nd ed. H. Lyr, ed. Gustav Fischer Verlag, Jena, Germany.

10. Forster, B, and Staub, T. 1996. Basis for use strategies of anilinopyrimidine and phenylpyrrole fungicides against Botrytis cinerea. Crop Prot. 15:529-537.

11. Gilpatrick, J. D. 1982. Case study 2: Venturia on pome fruits and Monilinia on stone fruits. Pages 195-206 in: Fungicide Resistance in Crop Protection. J. Dekker and S. G. Georgopoulos, eds. Centre for Agricultural Publishing and Documentation, Wageningen, The Netherlands.

12. Gisi, U. 1986. Synergistic interaction of fungicides in mixture. Phytopathology 86:12731279.

13. Hilber, U., and Hilber-Bodmer, M. 1998. Genetic basis and monitoring of resistance of Botryotinia fuckeliana to anilinopyrimidines. Plant Dis. 82:496-500.

14. Jones, A. L. 1981. Fungicide resistance: Past experience with benomyl and dodine and future concerns with sterol inhibitors. Plant Dis. 65:990-992.

15. Jones, A. L. 1995. A stewardship program for using fungicides and antibiotics in apple disease management programs. Plant Dis. 79:427-432.

16. Knauf-Beiter, G., Dahmen, H., Heye, U., and Staub, T. 1995. Activity of cyprodinil: Optimal treatment timing and site of action. Plant Dis. 79:1098-1103.

17. Köller, W. 1990. Fungicide resistance in plant pathogens. Pages 679-720 in: CRC Handbook of Pest Management in Agriculture, 2nd ed., Vol. 2. D. Pimentel, ed. CRC Press, Boca Raton, FL.

18. Köller, W. 1996. Recent developments in DMI resistance. Pages 301-311 in: Modern Antifungal Compounds. H. Lyr, P. E. Russel, and H. D. 
Sisler, eds., Intercept Ltd., Andover, UK

19. Köller, W., Parker, D. M., and Reynolds, K. L. 1991. Baseline sensitivities of Venturia inaequalis to sterol demethylation inhibitors. Plant Dis. 75:726-728.

20. Köller, W., and Scheinpflug, H. 1987. Fungal resistance to sterol biosynthesis inhibitors: A new challenge. Plant Dis. 71:1066-1074.

21. Köller, W., and Wilcox, W. F. 1999. Evaluation of tactics for managing resistance of Venturia inaequalis to sterol demethylation inhibitors. Plant Dis. 83:857-863.

22. Köller, W., Wilcox, W. F., Barnard, J., Jones, A. L., and Braun, P. G. 1997. Detection and quantification of resistance of Venturia inaequalis populations to sterol demethylation inhibitors. Phytopathology 87:184-190.

23. Köller, W., Wilcox, W. F., and Jones, A. L. 1999. Quantification, persistence and status of dodine resistance in New York and Michigan orchard populations of Venturia inaequalis. Plant Dis. 83:66-70.

24. Kosman, E., and Cohen, Y. 1996. Procedures for calculating and differentiating synergism and antagonism in action of fungicide mixtures. Phytopathology 86:1280-1283.

25. Kunz, S., Deising, H., and Mendgen, K. 1997. Acquisition of resistance to sterol demethylation inhibitors by populations of Venturia in- aequalis. Phytopathology 87:1272-1278.

26. Laird, D., Tally, A., Margot, P., Kung, R., and Knauf-Beiter, G. 1998. Trifloxystrobin, a new fungicide for use in apples and grapes. (Abstr.) Phytopathology 88:S51.

27. Leung, H., Nelson, R. J., and Leach, J. E. 1993. Population structure of plant pathogenic fungi and bacteria. Adv. Plant Pathol. 10:157-206.

28. Levy, Y., Benderly, M., Cohen, Y., Gisi, U., and Bassand, D. 1986. The joint action of fungicides in mixtures: comparison of two methods for synergy calculations. EPPO Bull. 16:651-657.

29. Margot, P., Huggenberger, J., and Amrein, J. 1998. CG 279202: A new broad-spectrum strobilurin fungicide. Proc. 1998 Brighton Conf. Pests Dis. 1998:375-382.

30. Olaya, G., and Köller, W. 1999. Diversity of kresoxim-methyl sensitivities in baseline populations of Venturia inaequalis. Pestic. Sci. 55:1083-1088.

31. Olaya, G., Zheng, D., and Köller, W. 1998. Differential responses of germinating $V$. inaequalis conidia to kresoxim-methyl. Pestic. Sci. 54:230-236.

32. O'Leary, A. L., Jones, A. L., and Ehret, G. R. 1987. Application rates and spray intervals for apple scab control with flusilazol and pyrifenox. Plant Dis. 71:623-626.

33. Richter, D. L. 1987. Synergism-A patent point of view. Pestic. Sci. 19:309-315.

34. Scheinpflug, H. 1988. Resistance management strategies for using DMI fungicides. Pages 93-94 in: Fungicide Resistance in North America. C. J. Delp, ed. APS Press, St Paul, MN.

35. Schwabe, W. F. S., Jones, A. L., and Jonker, J. P. 1984. Greenhouse evaluation of the curative and protective action of sterol-inhibiting fungicides against apple scab. Phytopathology 74:249-252.

36. Szkolnik, M. 1981. Physical modes of action of sterol-inhibiting fungicides against apple diseases. Plant Dis. 65:981-985.

37. Wilcox, W. F., Wasson, D. I., and Kovach, J. 1992. Development and evaluation of an integrated, reduced-spray program using sterol demethylation inhibitor fungicides for contro of primary apple scab. Plant. Dis. 76:669-677.

38. Ypema, H. L., and Gold, R. E. 1999 Kresoxim-methyl. Modification of a naturally occurring compound to produce a new fungicide. Plant Dis. 83:4-19.

39. Zheng, D., and Köller, W. 1997. Characterization of the mitochondrial cytochrome $b$ gene from Venturia inaequalis. Curr. Genet. 32:361-366. 